\title{
Simulation and Fabrication of Open-Type Boiler of Fish Cracker Production Line
}

\author{
Mohd Zaidi Sidek \\ Faculty of Manufacturing Engineering, Universiti \\ Malaysia Pahang, 26600 Pekan, Pahang \\ zaidisidek@ump.edu.my, \\ Mohd Syahidan Kamarud in \\ Faculty of Manufacturing Engineering, Universiti \\ Malaysia Pahang, 26600 Pekan, Pahang
}

Boiling process is performed at the final stage in fish cracker processing and it is a longest process. It creates a bottleneck and limits the daily production of fish cracker. Traditionally, fire woods are used to heat the boiler. The invention of dieselfired boiler has improved the process but there are still some issues at the station. Therefore, a new boiler is designed to improve the boiling process by using LPG burner which has 2.9 $\%$ higher calorific value than diesel. The boiler designed was simulated to study the heat convection inside the boiler by using SolidWorks Flow Simulation to analyze the temperature distribution inside the new boiler. Multiple layers bottom plate of the boiler consist of an aluminium plate sandwiched between two stainless steel plates is used to increase the rate of heat transfer from the flame into the water inside the boiler. The result from the simulation proves that the multiple layers bottom plate of the boiler has a higher rate of heat tran sfer than the single layer plate where the time taken for water to boil is $42.2 \%$ shorter than the single stainless steel layer bottom plate boiler.

\section{INTRODUCTION}

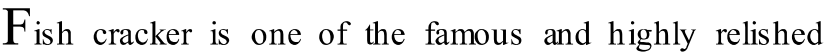
snack foods in Malaysia and it is orig inated from east coast of peninsular Malaysia [1]. It is well known and highly demanded due to its crispy on the outside but tender on the inside if it is fried. Besides, fish cracker can be eat by just boil it which gives fishier flavour according to some people. Both fried and boiled fish cracker is best to be eaten with special fish cracker chilli sauce. The main ingredient of fish cracker is fish, sago flour, salt and water. The high requirement of fish cracker in the market urge entrepreneurs to increase their production but they face a lot of problem to fulfil the market demand. In the production of fish cracker, most manufacturers are still using traditional manufacturing practices with low competitiveness and poor efficiency which limit the daily production of the fish cracker. As a result, these manufacturers cannot meet the demand of the customer. Thus, there is a necessity to employ a standard processing procedure in order to keep the quality while meet ing the high production to provide the consumer demands of the delicious fish cracker. There are several stages of processing that are needed to be taken to make fish cracker as shown in Figure 1.

\author{
syahidankamarudin@gmail.com, \\ Mohamad Nafis Jamaluddin \\ Faculty of Manufacturing Engineering, Universiti \\ Malaysia Pahang, 26600 Pekan, Pahang \\ mohdnafis89@gmail.com
}

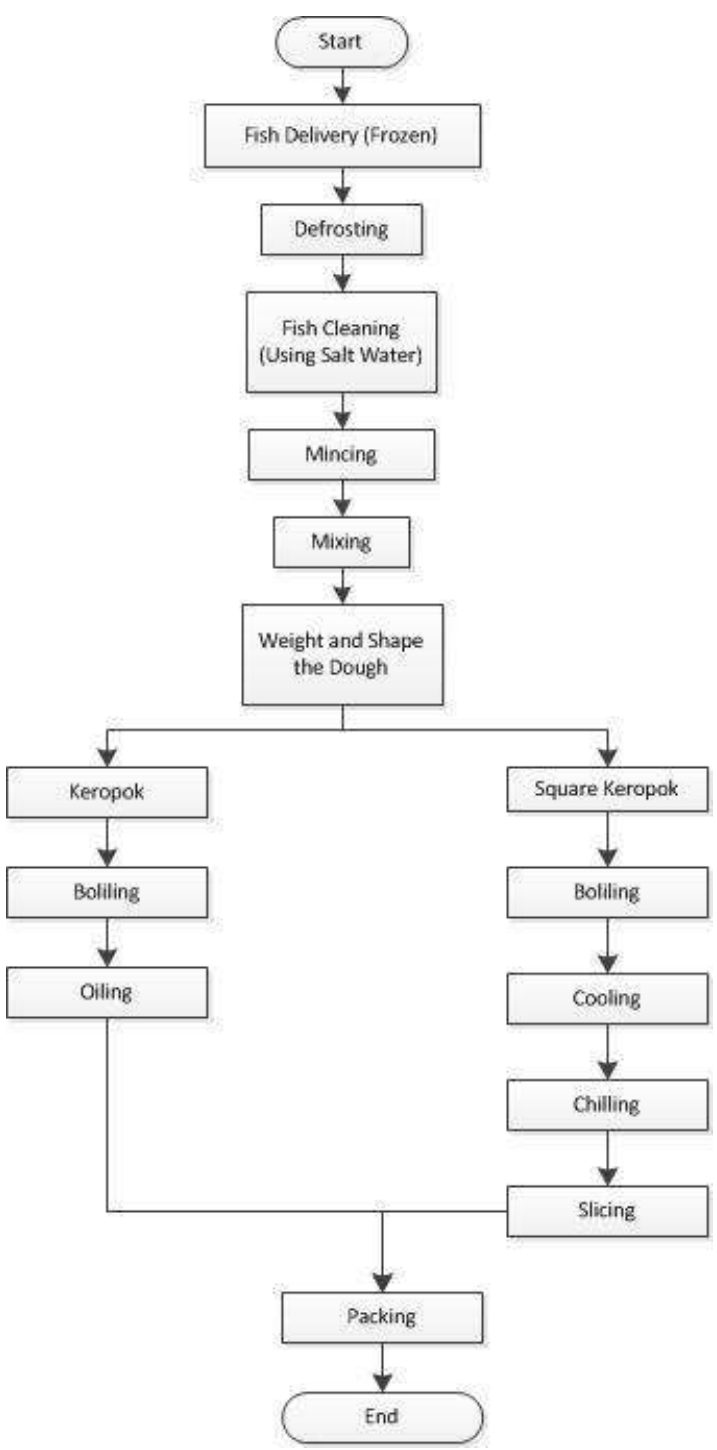

Fig. 1.Process sequence in fish cracker manufacturing Previously, fish cracker manufacturers carry out the processes manually such as the process to roll the dough into huge sausage-like fish cracker and shaping square fish cracker is still being done manually. In addition, the process to boil the fish cracker is done traditionally by boiling water from burning firewood. This method is not very efficient where it is difficult to control the fire and it also produces smoke and soot to the surroundings. Therefore, at that moment, the manufacturers cannot produce high production of fish cracker to meet the market demand.

Nowadays, Small and Medium Industry (SMI) sector has improved very well in the term of their manufacturing method. The technology that is used in other food 
processing industry such as nugget, burger and meat ball has influenced many local foods including fish cracker to be commercialized [2]. The fish cracker manufacturers have improve their processes hence increase the production of fish cracker by the use of automated mach ines to perform a certain task such as the processes to mince and mixing the kneaded fish meat. Other than that, automatic diesel fire-tube burner is installed to the boiler to perform the task boiling of fish cracker. Automated processes can help fish cracker manufacturers to increase the production to meet the market demand.

Fish cracker industry has caught the eye of the Malaysian government therefore it is included into East Coast Economic Region (ECER) as the east coast of peninsular Malaysia is rich in resources and the raw material for fish product food. The fish industry is put under food and halal product initiatives.

Traditionally, the process of boiling fish cracker is by burning firewood. This method is not suitable as it is hard to control the fire, efficiency is low where a lot of firewood is used and the burning of firewood produces smoke and soot on the surrounding. Currently, the invention of fire tube burner by using diesel fuel has improved the boiling process. This burner does not need a worker to control the fire as the diesel injection is automatically control via temperature sensor that sense the temperature of the water inside the tank. Furthermore, the smoke from burning diesel is channelled away from the working area. This is a lot better than the previous one as the water boils faster by using this method.

Apart from that, the burner still has few things to be improved because the uneven temperature distribution as the temperature of water near the diesel burner is high but it decrease as it moves far from the burner. The result of this problem is the fish cracker that are put on the side near the burner cook faster than the fish cracker that are placed further from the burner which lead to the bottleneck on the production.

The aims for this study are to design a new boiler and to simu late the heat convection inside the new boiler by using Solidworks Flow Simulation.

\section{LITERATURE REVIEW}

\section{A. Fish Cracker Industry}

Malaysia is unique country of different cultures that has led to in varieties of foods. It is important that these traditional foods are preserved for future generations. By using modern technologies and traditional techniques, manufacturers could produce more hygienic way of processing and preserving food [3]. Thus, there is an urgent need to refine the processing of traditional foods in response to new societal needs. Refining and sustaining traditional foods are essential in facing the forces of globalization [4].

In the production of fish cracker, most producers are still using traditional manufacturing practices with low competitiveness and poor efficiency. Therefore, there is a need to employ a standard processing procedure in order to maintain the quality while meeting consumer demands for safety, quality and nutritional value of these foods. Traditionally, fish cracker is precooked by boiling in water. Study by Bakar (1983) reviewed the boiling and steaming methods in processing fish cracker. The researcher found that steaming of fish cracker does not prove to be feasible and the study suggested several modifications in the processing steps in fish cracker preparation are essential. On the other hand, [1] reviewed in terms of sustaining and promoting of this local food, more publicity should be performed continuously and producers of fish cracker must achieve consistent quality and safety as it represents Malaysia's identity. Traditional fish cracker production methods result in products of poor quality, with uneven expansion characteristics, dark objectionable colours and varying shapes, sizes and thicknesses as well as low hygiene [6]. Siaw, Idrus, \& Yu (2007) have attempted to upgrade product quality. They have introduced mechanization and standardization into fish cracker making. Their process is less time consuming and gives a better-quality product compared to the traditionally produced fish cracker. The two essential ingredients in fish cracker making are starch and fish. Fish such as 'Ikan Parang' (Chirocentrus dorab), 'Ikan Tamban beluru' (Clupea leiogaster) and 'Ikan Selayang' (Decapterus macrosoma) are preferred although other fishes are also used for making fish cracker. Tapioca or sago starch is used but sago starch is said to give the best product in terms of texture and flavor [8]. Fish cracker can be eaten as soon as it is boiled and together with chili sauce.

\section{B. Bottleneck In Fish Cracker Processing}

The purpose of boiling fish cracker is to precook for further processing although it is palatable with chili sauce for some people. According to [5], only 15 minutes of boiling required to achieve complete cooking of fish cracker while 3 hours is needed to achieve the same result by steaming. Processing conditions such as boiling of product can reduce microbial levels, although recontamination takes place during post-processing and handling of food [9].

\section{Boiler Specifications}

There are several factors that must be studied before designing a boiler such as material, heating configuration, temperature distribution and heat transfer rate [10]. Designing a boiler without a proper research on the topic will lead to a failure and will waste lots of money if the design is fabricated. Therefore, appropriate study on the boiler specifications should be done before designing it to ensure the new boiler will produce good heating characteristics and improved the production in the boiling station in fish cracker processing.

Temperature distribution plays an important role for a boiler in the boiling station as it will affect the cooking time for the fish cracker [11]. Uneven temperature distribution will lead to bottleneck where 10 to 15 minutes are taken to check whether all fish cracker are properly cooked. Therefore, the shape and the geometry of the boiler must be able to allow even temperature distribution inside the boiler. It is very crucial for the boiler to have the characteristic because it will solve the problem of different cooking time of the fish cracker. 
Another important factor in boiler specifications is the material selection for the boiler. Different material has their own characteristics such as mechanical properties, thermal properties, corrosion resistance and durability. Important aspect such as hygiene is vital in fish cracker processing as poor hygiene may lead to health illness such as food poisoning to the consumers. The contamination of surfaces by spoilage and pathogenic micro-organisms is a cause of concern in the food industry. One of the decisive arguments when choosing materials for processing line equipment, along with their mechanical and anticorrosive properties, has become hygienic status (low soiling level and high cleanability). Of these materials, stainless steel, which is widely used for constructing food process equipment, has previously been demonstrated to be highly hygienic [12]. However, stainless steel can be produced in various grades and finishes, affecting bacterial adhesion because of their various topographies and physic-chemical properties [13]. The main difference between commercially available grades is their relative composition in iron, chromium and nickel. Austenitic stainless steels containing chromium and nickel, such as AISI 304, are widely used in the food industry because of their high resistance to corrosion by food products and detergents.

Other elements may be added to improve anticorrosive properties, such as molybdenum in AISI 316, often used in dairies. Other materials such as ferritic stainless steel are used in various applications because of how easily they can be formed and welded (catering). Moreover, one grade can be obtained in more or less rough finishes such as pickling finish (2B) and bright annealed (2R), depending on their final steel making process [14]. Higher heat conductivity of the cooper used as heating plate can result in short recovery time [15].

Currently, the invention of fire tube burner by using diesel fuel has improved the boiling process. This burner does not need a worker to control the fire as the diesel injection is automatically control via temperature sensor that sense the temperature of the water inside the tank. Apart from that, the burner still has few things to be improved because the uneven temperature distribution. The result of this problem is the fish cracker that are put on the side near the burner cook faster than the fish cracker that are placed further from the burner which lead to the bottleneck on the production.

In addition to the burner, it also has a blower to circulate the heat along with vents that remove the by-products of combustion and allow fresh air to flow into the burner for a steady burn rate. One of the most important aspects in making a good heating system is the design of the heating system and its tank. Therefore, factors such as better temperature distribution and control, faster cooking, less energy, safer operation, better sanitation and flexibility must be taken into account in considering the design. Plus, the shape of the heating unit is also an important design consideration. Ekundayo (1994) stated that the optimum configuration to achieve the most steady-state rate of convection was with the heating element placed in the lower half of the tank.

Research Methodology

In this analysis, the current boiler design and application are recorded to be analysed. Then, a new design fish cracker boiler created to overcome the issues of the current boiler.

The design of the new fish cracker boiler is based on several considerations and factors which will be explained next section. The drawing of the new boiler is as shown in Figure 2.

To verify the simulations, an experimental test method is used to examine if a correlation between the test method and the simulations exist. The aim is to find a parameter that can be evaluated in the simulation. In the experiment, a Liquefied Petroleum Gas (LPG) burner is use to heat 1.15 L of water in a pot until the point of boiling as shown in Figure 3. The same parameters from the experiment will be used in the simulation and the result of the simulation is compared with the experimental result to see whether the simulation is valid or not.

With the validated simu lation, the design of the new boiler can be simulated to analyse the heat convection characteristics inside the new boiler by using the similar method that is used in the simulation validation in order to determine whether the new design is capable to solve the problem of bottleneck hence increase the production of fish cracker in the factory.

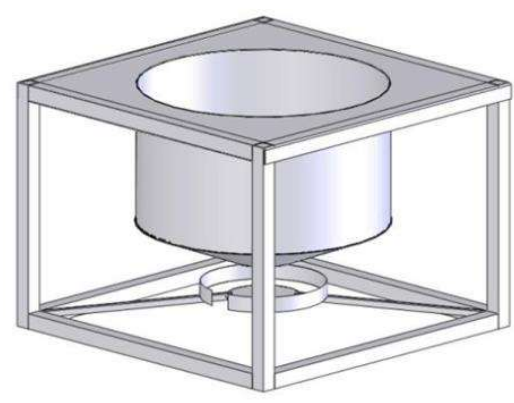

Fig. 2. Design of fish cracker boiler

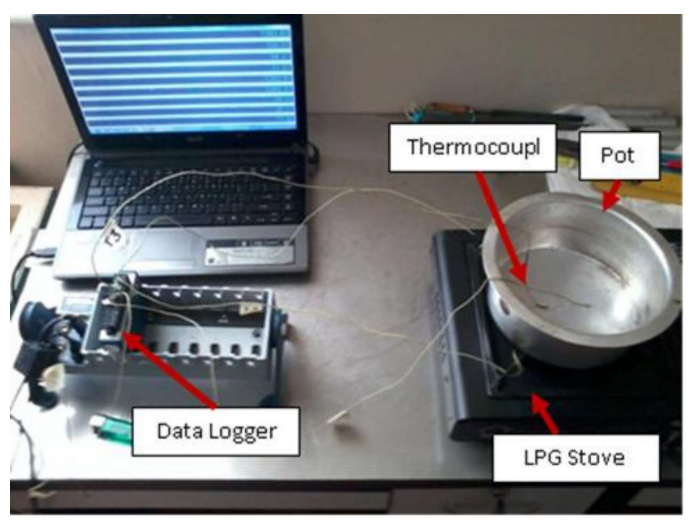

Fig. 3.Experiment apparatus

\section{RESULT AND DISCUSSION}

\section{A. . Boiler Design}

There are several considerations that must be included in designing the new boiler. The temperature distribution and material selection in fabricating the boiler were the main is sues to be concerned and as an innovation of the boiler design, an insulation system of the boiler was created. 
To avoid the uneven distribution of the temperature, a centred-stove boiler concept was selected with a big cylindrical shape replacing the u-shape heating system. The current u-shape, the water boils faster on the nearest side to the blower and vice vers a on the side further from the blower.

Figure 4 shows the drawing of the tank that is used to boil fish cracker at the factory. The fire from diesel burning flows inside the hollow tube inside the tank which heat is transferred to the water. To prove that the temperatures are varies inside the tank; thermocouples are used to measure the water temperature at point $A$, point $B$ and point $C$. The temperature is measured and the graph of the temperature at the points is shown in Figure 5.

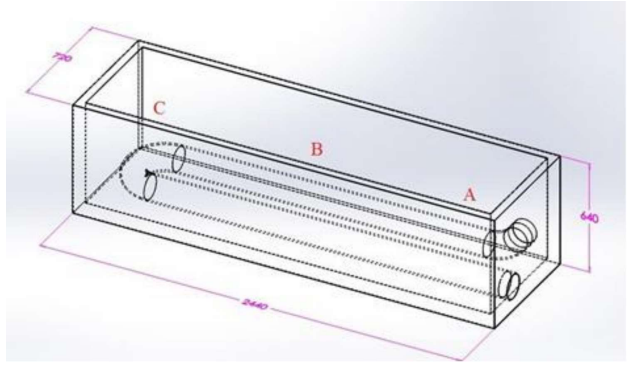

Fig. 4. Tank drawing

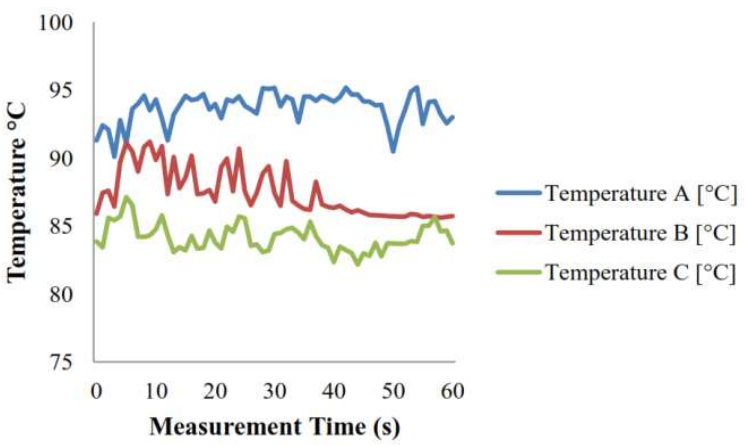

Fig. 5. Temperature distribution in tank

\subsection{Simulation Validation}

For the validation purpose of the simulations, an experimental test method is used to examine if a correlation between the test method and the simulations exist. The aim is to find a parameter that can be evaluated in the simulation. In the experiment, an LPG burner is used to heat $1.15 \mathrm{~L}$ of water in a pot until the point of boiling. The same parameters from the experiment will be used in the simulation and the result of the simulation is compared with the experimental method. The measured temperature of the flame from LPG burning in the experiment is 820 ${ }^{\circ} \mathrm{C}$. This parameter will be used at the bottom plate of the pot in the simulation validation as wall temperature boundary condition as shown in the Figure 6 .

Graph in the Figure 6 shows the water temperature $\left({ }^{\circ} \mathrm{C}\right)$ versus time (minutes) for the experiment. The temperature steadily increased from $27.32^{\circ} \mathrm{C}$ until maintained at 84.97 ${ }^{\circ} \mathrm{C}$ after 7.23 minutes of heat applied.

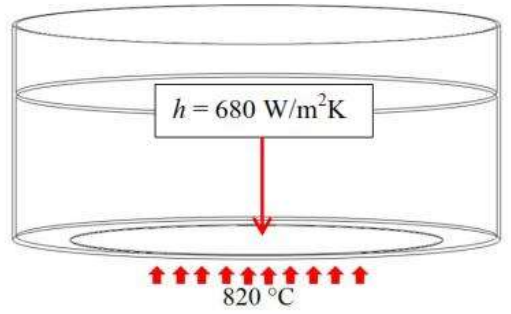

Fig. 6. Me as ure d fl ame te mper ature

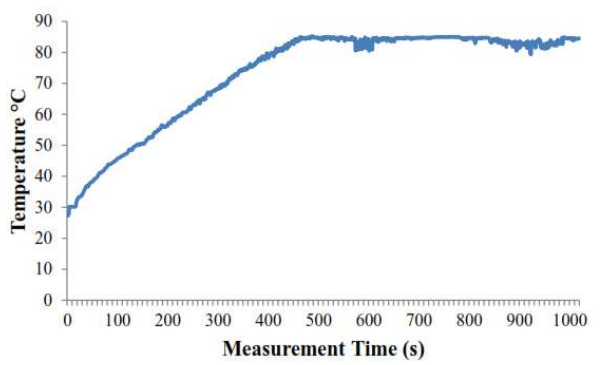

Fig. 7. Experimental result

Figure 8 shows the graph of temperature over time for the simulation on the pot. The graph is automatically plotted by Flow Simulation software. The temperature of water increased steadily from $26.72{ }^{\circ} \mathrm{C}$ until maintain at 87.74 ${ }^{\circ} \mathrm{C}$ after 6.33 minutes.

From both graphs, we can see that the temperature of water for both experiment increased steadily until maintain at temperature around $84^{\circ} \mathrm{C}$ to $87^{\circ} \mathrm{C}$ after $820^{\circ} \mathrm{C}$ of flame temperature is applied at the bottom surface of the pot. The simulation takes shorter time which is 6.33 minutes while the experiment takes 7.23 minutes. This is due to the ideal condition in the simulation such as the purity of water in the simulation differs slightly with the water that is used in the simulation. Plus, the flame temperature in the simulation is maintained at $820{ }^{\circ} \mathrm{C}$ from the first second until the end of the simulation. Meanwhile, the flame temperature in the experiment takes a few seconds to reach $820^{\circ} \mathrm{C}$. Therefore, the slight variation in both result can be tolerate thus validate the simulation that is done in SolidWorks Flow Simulation software and the same simulation can be applied at the new boiler to simulate the finite volume analysis to study the heat convection at the inside of the boiler.

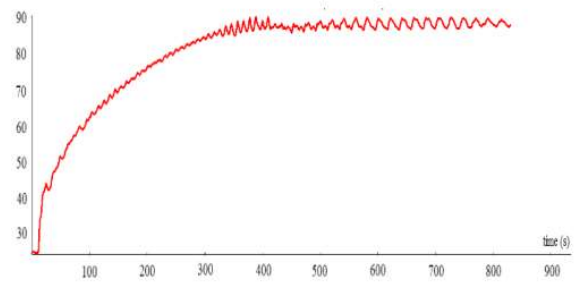

Fig. 8. Simul ation result graph 
The result of the finite volume simulation on the new boiler is illustrated in the Figure 9 which show the temperature contour cut plot from the front plane of the boiler. This cut plot is the temperature distribution inside the boiler after 15.83 minutes of heating. From the cut plot contour, temperature distribution inside the boiler range from $97.36{ }^{\circ} \mathrm{C}$ to $100.16^{\circ} \mathrm{C}$.
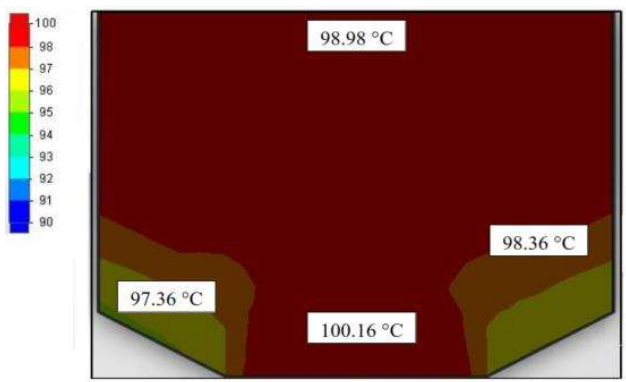

Fig. 9. Temperature contour cut pl ot

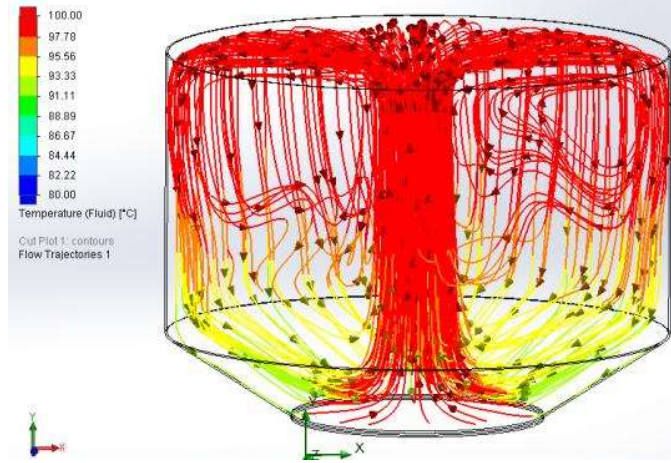

Fig. 10.Flow trajectory of water inside the boiler

The new boiler has a better temperature distribution which may improve the boiling process of fish cracker and increase the productivity. The time taken to ensure all fish cracker is fully cooked after 15 minutes can be reduced as all fish cracker inside the boiler are cooked at temperature range from $97.36{ }^{\circ} \mathrm{C}$ to $100.16{ }^{\circ} \mathrm{C}$. Even temperature distribution is achieved in this boiler because of the shape of this boiler and the heat is applied at the bottom part of the boiler which makes the water to circulate to all part inside the boiler.

From the flow trajectory of the water inside the boiler, the circulation of water can be determined as shown in the Figure 10. The circulation is due the buoyancy effect inside the boiler where hotter water moves upwards due to lower density and vice versa for cooler water. Although the temperature of water is just slightly varied, the difference in density will determined the movement of the water which creates the flow inside the boiler. The line with arrows in the Figure 10 shows the direction of the water flow. In the middle part of the boiler have hotter water flowing upward. As it reaches the top surface, the temperature of the water will drop a little and move downward by the side part of the boiler and the cooler water will be heated again as it reaches the bottom part where the heat is applied. This result proves the finding by Jullien, Bénézech, Carpentier, Lebret, \& Faille, (2003) that is the optimum configuration to achieve the most steady- state rate of convection was with the heating element placed in the lower half of the tank.

\section{B. Comparison of Single Layer Plate and Multiple Layer Plate}

Figure 11 shows the temperature over time of boiling process that is simulated on the boiler with multiple layers bottom plate. The time taken for the water to reach $100^{\circ} \mathrm{C}$ is 15.3 minutes.

The graph in Figure 12 shows the temperature over time of boiling process that is simulated on the boiler with single layer bottom plate. The time taken for the water to reach $100{ }^{\circ} \mathrm{C}$ is 26.47 minutes.

From the graphs shown in Figure 11 and Figure 12, the boiler with multiple layers bottom plate will boils the water faster than the boiler with single layer bottom plate. This proves that the multiple layer bottom plate has a higher rate of heat transfer which transfers the heat faster from the LPG flame into the water through the multiple layers bottom plate.

$$
\begin{aligned}
& \text { Percentage } \\
& =\frac{\text { Single layer time }- \text { Multiple layer time }}{\text { Single layer time }} \times 100 \%
\end{aligned}
$$

Percentage $=42.2 \%$

The new boiler with multiple layer bottom plates has higher rate of heat transfer by $42.2 \%$ compared to single layer bottom plate. Thus, the multip le layer bottom plate is capable able to increase the daily rate of fish cracker production.

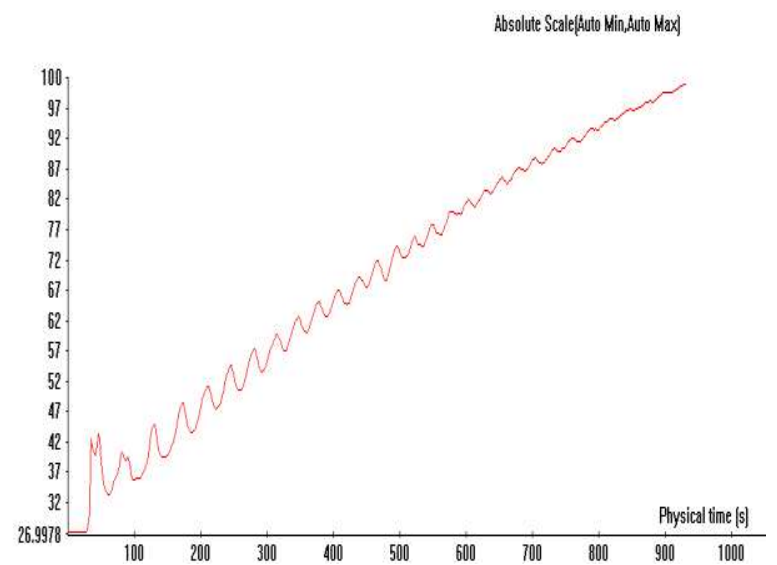

Fig. 11. Multiple plies plate graph

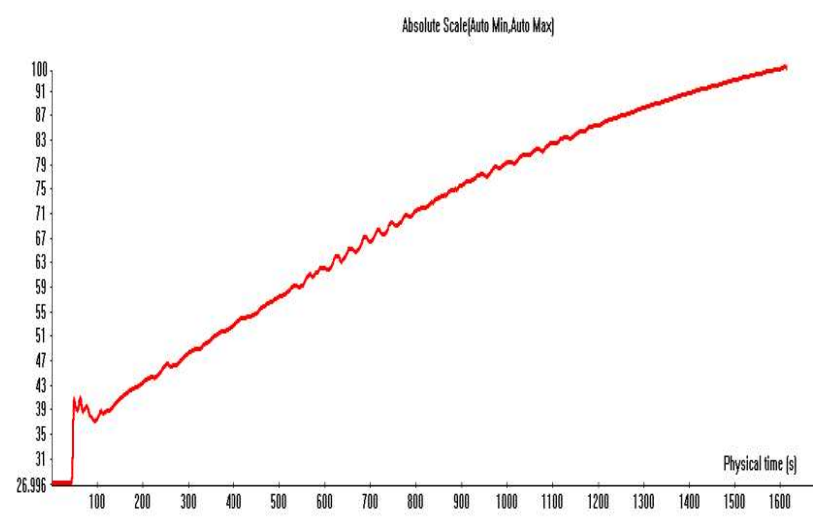


Fig. 12. Single ply plate graph

\section{CONCLUSION}

New boiler design can improved the heating rate and temperature distribution of water inside the boiler thus improving the boiling process of fish cracker where the time taken to ensure that all fish cracker is fully cooked can be reduced thus solving the bottleneck problem which is due to 10 to 15 minutes taken to check for all fish cracker to fully cook. All fish cracker that are boil inside this boiler will take 15 minutes to fully cooked as the temperature is even distributed inside this boiler which is around $97.36^{\circ} \mathrm{C}$ to $100.16^{\circ} \mathrm{C}$.

Multiple layers bottom plate is better than single layer because it has $42.2 \%$ higher rate of heat transfer by single layer bottom plate boiler as the multiple layers configuration reduced the total thermal resistance. The layer of alumin iu m in between two stainless steel layer has improved the rate of heat transfer. This layer configuration is preferable to be used since the stainless steel has low conductivity but the boiler must be made of corrosion resistance material and provide good hygiene.

\section{RECOMMENDATION FOR FUTURE RESEARCH}

Based on the findings of the present investigation, the following recommendations are made for further research: The further improvement for the new boiler can be made to increase the performance of the boiler such by using higher thermal conductivity material to replace the aluminium with copper that has $401 \mathrm{~W} / \mathrm{mK}$ which is almost twice as large as the value of thermal conductivity of alu min ium. The study on the boiler with copper plate in between stainless steel at the bottom plate can be done by using the same method used in this simulation.

The system to control the LPG burner can be developed to save the fuel consumption at the boiling station in keropok ikan industry. This system also will eliminate the need of worker to monitor the LPG flame. Furthermore, this system will also reduce the fuel cost for boiling fish cracker.

ii. Samples with fiber volumetric ratios of 1.5 kg.m-3 indicated better corrosion resistance compared to the other samples.

iii. In this research, using coral aggregate for producing concrete samples showed that this concrete composition was not a practical composition. Corrosion rate in this concrete was at least twice that was shown in siliceous concrete.

iv. The results show that $6 \mathrm{~mm}$ length fibers were not the suitable size to be used in concrete. The result of using fibers with length of 12 and $19 \mathrm{~mm}$ was approximately the same, with the optimum size being $12 \mathrm{~mm}$.

v. Apart from increasing corrosion resistance, the presence of polypropylene fibers decreased the permeability, volumetric expansion and contraction of concrete, which in turn had reduced the chance of concrete cracking.

\section{ACKNOWLEDGMENT S}

This research was made possible with a scholarship from Ministry of Highr Education, Malaysia and support from University Malaysia Pahang (UMP).

\section{References}

1. M. Omar, "Sustaining traditional food: consumers' perceptions on physical characteristics of keropok lekor or fish snack.," Int. Food ..., 2011.

2. M. A. Tukiran, "Development of an automated keropok lekor cutting machine using pneumatic system," Universiti Teknikal Malaysia Melaka, 2009.

3. K. de Roest and A. Menghi, "Reconsidering 'Traditional' Food: The Case of Parmigiano Reggiano Cheese," Sociol. Ruralis, vol. 40, no. 4, pp. 439-451, Oct. 2000.

4. A. Trichopoulou, S. Soukara, and E. Vasilopolou, "Traditional foods: a science and society perspective," Trends Food Sci. Technol., vol. 18, no. 8, pp. 420-427, Aug. 2007.

5. J. Bakar, "Keropok Lekor-Boiling and Steaming Methods of Processing," Pertanika, vol. 6, no. 3, pp. 56-60, 1983.

6. S. Y. Yu, J. R. Mitchell, and A. Abdullah, "Production and acceptability testing of fish crackers ('keropok') prepared by the extrusion method," Int. J. Food Sci. Technol., vol. 16, no. 1, pp. 51-58, Jun. 2007.

7. C. L. Siaw, A. Z. Idrus, and S. Y. Yu, "Intermediate technology for fish cracker ('keropok') production," Int. J. Food Sci. Technol., vol. 20, no. 1, pp. 17-21, Jun. 2007.

8. T. Taewee, "Cracker 'Keropok': A review on factors influencing expansion," Int. Food Res. J., vol. 18, no. 3, pp. 855-866, 2011.

9. N. M. Sachindra, P. Z. Sakhare, K. P. Yashoda, and D. Narasimha Rao, "Microbial profile of buffalo sausage during processing and storage," Food Control, vol. 16, pp. 31-35, 2005.

10. S. D. Pohekar, D. Kumar, and M. Ramachandran, "Dis semination of cooking energy alternatives in India-a review," Renew. Sustain. Energy Rev., vol. 9, no. 4, pp. 379-393, Aug. 2005.

11. M. N. Khaizura, S. Loh, and H. Zaiton, "Quantification of Coliform and Escherichia coli in Keropok lekor (Malaysian Fish Product) During Processing.,” J. Appl. Sci. ..., 2010.

12. J. T. Holah and R. H. Thorpe, "Cleanability in relation to bacterial retention on unused and abraded domestic sink materials," J. Appl. Bacteriol., vol. 69, no. 4, pp. 599-608, Oct. 1990.

13. L. R. Hilbert, D. Bagge-Ravn, J. Kold, and L. Gram, "Influence of surface roughness of stainless steel on microbial adhesion and corrosion resistance," Int. Biodeterior. Biodegradation, vol. 52, no. 3, pp. 175-185, Oct. 2003. 
14. L. Boulané-Petermann, "Processes of bioadhesion on stainless steel surfaces and cleanability: A review with special reference to the food industry.," Biofouling, vol. 10, no. 4, pp. 275300, Jan. 1996.

15. S. Rodgers, "Innovation in food service technology and its strategic role," Int. J. Hosp. Manag., vol. 26, no. 4, pp. 899-912, Dec. 2007.

16. C. O. Ekundayo, "Heat Transfer In Enclosures: Ovens," Cranfield University, 1994.
17. C. Jullien, T. Bénézech, B. Carpentier, V. Lebret, and C. Faille, "Identification of surface characteristics relevant to the hygienic status of stainless steel for the food industry," J. Food Eng., vol. 56, no. 1, pp. 77-87, Jan. 2003. 